\title{
Social Entrepreneurship from the Perspective of Opportunity: Integration Analysis Based on Timmons Process Model
}

\author{
Xiaohua Su${ }^{1}$, Yan Zhou ${ }^{1 *}$, Shujun Zhang ${ }^{2}$ \\ ${ }^{1}$ School of Management, Jinan University, Guangzhou, China \\ ${ }^{2}$ School of Management, Sun Yat-sen University, Guangzhou, China \\ Email: ^2692984680@qq.com
}

How to cite this paper: Su, X.H., Zhou, Y. and Zhang, S.J. (2019) Social Entrepreneurship from the Perspective of Opportunity: Integration Analysis Based on Timmons Process Model. Journal of Human Resource and Sustainability Studies, 7, 438-461.

https://doi.org/10.4236/jhrss.2019.73029

Received: April 26, 2019

Accepted: September 17, 2019

Published: September 20, 2019

Copyright $\odot 2019$ by author(s) and Scientific Research Publishing Inc. This work is licensed under the Creative Commons Attribution International License (CC BY 4.0).

http://creativecommons.org/licenses/by/4.0/

(C) (i) Open Access

\begin{abstract}
As an effective means to solve social problems, social entrepreneurship has received extensive attention from academic and practical circles. Although social entrepreneurship research has achieved great development in the past decade, the research results in various fields are still scattered and lack of a systematic logical framework, which hinders its rapid growth into a more potential research field. Combining the Timmons entrepreneurial model with Shane and Venkataraman's entrepreneurial opportunity process research ideal, we take the sources, identification and utilization of social entrepreneurship opportunities as the basis, and at the same time contact with social entrepreneurship subjects and resources to deeply explore the interaction and dynamic balance between various elements from the perspective of entrepreneurship process. Then, we explore the constructive integration analysis framework of social entrepreneurship, which has important theoretical and practical significance for further deepening and expanding social entrepreneurship research.
\end{abstract}

\section{Keywords}

Opportunity Perspective, Social Entrepreneurship, Timmons's

Entrepreneurial Process Model

\section{Introduction}

Defined as a process in which resources are creatively combined to explore and exploit opportunities, to meet social needs or stimulate social change, social entrepreneurship (SE) is seen as a key factor to reduce poverty, improve the environment and increase employment [1]. In the past decade or so, social entre- 
preneurship has achieved remarkable progress in solving social problems in developing countries [2]. Meanwhile, it has also attracted extensive attention from academia being its central concerns different from the traditional commercial entrepreneurship [3]. Leading management and entrepreneurship journals continue to publish papers related to social entrepreneurship, unravelling its innovative role in solving social problems and promoting economic development. As a new research field with theoretical and practical value, social entrepreneurship has become an important social transformation under the complex market environment and institutional background [4]. However, the fact is that related research is still in the stage of exploration and development and the relevant theoretical framework incomplete. It leads to the scattered theoretical results failing to fully understand the research topic. So, the key to solve research deficiencies is to analyze the internal logic of social entrepreneurship by tracking the whole process of entrepreneurial behavior.

Similar to entrepreneurial research, early social entrepreneurship research inherits the traditional entrepreneurial traits theory, focusing on the personal factors of entrepreneurs (such as personal traits, entrepreneurial motivation) and analyzing the influence of entrepreneurs from a cognitive perspective. Later research gradually introduces the entrepreneurship process theory, including a series of activities such as social entrepreneurship opportunity cognition, resource acquisition and legitimacy establishment. They analyze the action law of social entrepreneurship from the perspective of process and explain the entrepreneurship results with entrepreneurial behavior. It realizes the change of research content from "who is the social entrepreneur or social enterprise" to "what is the main body of social entrepreneurship doing" and "what is the result of social entrepreneurship". However, the research on different topics ignores the connection and divides the interaction among social entrepreneurial subjects, entrepreneurial behaviors, and entrepreneurial environments. While the fact is that the particularity of social entrepreneurship is not only the specific behavior of a very small number of members of society, but also the survival and development process of the organization based on the identification, utilization and development of entrepreneurial opportunities [5]. In other words, social entrepreneurship is an organizational practice initiated by entrepreneurs, implemented through entrepreneurial activities, and incorporated into an entrepreneurial environment. The different elements jointly determine the success or failure of social entrepreneurship. However, the existing research obviously ignores this internal logic, which hinders the development of social entrepreneurship research. Therefore, when breaking through this limitation, it is very important to deeply explain the process form an analysis framework of "factors-behaviors-effects". Although there are already some excellent reviews, they tend to focus on the analysis of specific problems within social entrepreneurship. For example, they either explain the connotation of the relevant concepts of social entrepreneurship, its causes, influencing factors and the mixed characteristics of social enterprises, or analyze the relationship between social entrepreneurship and social 
innovation, explore the measurement of social impact. It dispersedly summarizes the existing research results neglecting the systematic grasp of the entrepreneurial process. Especially, there is a lack of a complete analysis of the core element-opportunity. This research wants to integrate the existing social entrepreneurship research from the perspective of opportunity, that is, taking the social entrepreneurship opportunity as the core, combining the social entrepreneurship subject and resources, to explore the whole process of social entrepreneurship. Timmons's entrepreneurial process model perfectly integrates the key elements of entrepreneurship. And it is currently the most suitable model for the entrepreneurial process, taking into account the dynamics and complexity of entrepreneurship. It can achieve the proper connection between different research themes and help to outline the behavioral contour of social entrepreneurship. It could provide a suitable theoretical perspective for explaining how various factors are continuously and dynamically adjusted with the growth of entrepreneurship. Focusing on this goal, this study connects subjects, opportunities and resources to deeply explore the interaction and dynamic balance between various elements from the perspective of social entrepreneurship process. Then we conclusively construct a social entrepreneurship process model (as shown in Figure 1).

The contribution of this study is mainly reflected in the following aspects. First, it deepens the academic community's understanding of social entrepreneurship. At present, the results of limited social entrepreneurship research are scattered. Through a systematic review and sorting of the existing social entrepreneurship literature, this study constructs a research framework from three aspects: social entrepreneurship subjects (social entrepreneurs, social entrepreneurship organizations), entrepreneurship opportunities (sources, identification, development) and entrepreneurship resources (resource acquisition, legitimacy construction). We aim at revealing the behavioral essence and internal laws of social entrepreneurship, thus contributing to the rationality and prospect of social entrepreneurship. Second, this study enriches the research perspective of social entrepreneurship. As an important driving force for creating social value,

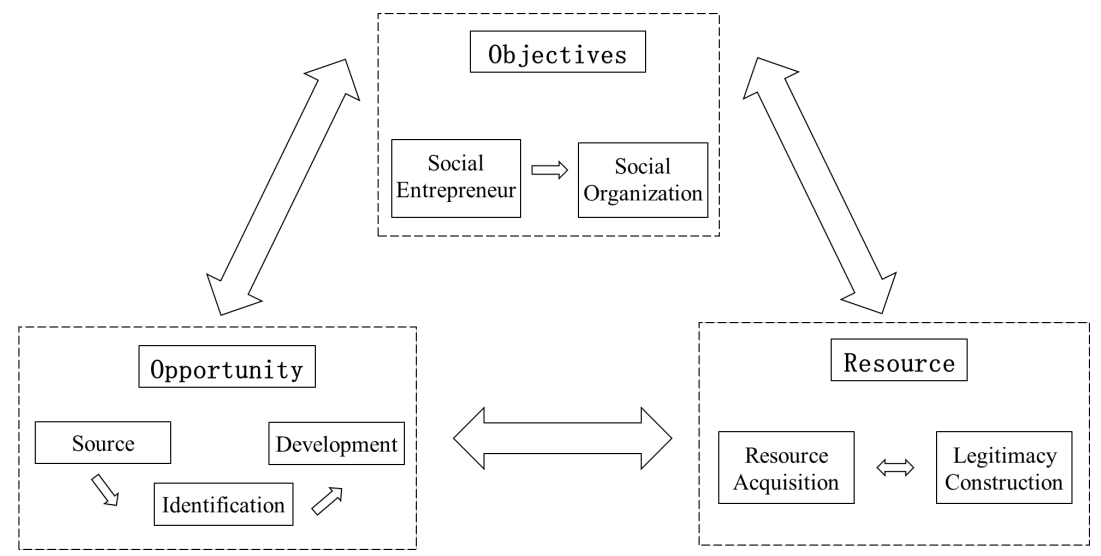

Figure 1. Social entrepreneurship process model. Source: Author's personal arrangement. 
social entrepreneurship needs a theoretical system that integrates all key entrepreneurial elements and analyzes its internal interaction mechanism. The combination of Timmons's process model and the idea of entrepreneurial opportunity process ingeniously links the key elements and main entrepreneurial behaviors in the process of social entrepreneurship, deeply exploring the mechanism of achieving social entrepreneurship goals. It helps to understand how each component of social entrepreneurship adapts to each other, which research gaps would continue to exist, and through which ways the corresponding most urgent gaps can be solved, thus provide a suitable perspective for studying and discussing how social entrepreneurship can survive and develop better.

\section{Research on Social Entrepreneurs}

Social entrepreneurship subjects mainly include entrepreneurs and organizations. Social entrepreneurs are regarded as a rare change agent. They have the ability, resources, and the internal motivation to encourage themselves to persist in completing social entrepreneurial activities. Unlike traditional entrepreneurs, social entrepreneurs are not driven by profit, but by social influences, also known as "prosocial motivation". Prosocial motivation is rooted in the values of universalism and benevolence. It emphasizes creating benefits for others, encourages social entrepreneurs to seek new means of social value creation, and profoundly affects the identification, development and use of social entrepreneurial opportunities [6]. Social entrepreneurs with altruistic thoughts show a strong tendency of empathy. As an important premise of social entrepreneurial willingness, empathy encourages social entrepreneurs to voluntarily take altruistic actions, putting social values above personal interests. And social entrepreneurs have a strong sense of self-efficacy, full of confidence in their ability to carry out entrepreneurial tasks related to social innovation [7]. Moreover, they have a strong sense of moral responsibility. Social entrepreneurs' perception of social morality can exert social pressure on them, thus affecting their decision-making and willingness to start a business [8]. Finally, social entrepreneurs have a socially innovative mindset that can effectively identify, develop and utilize social entrepreneurship opportunities. In addition, previous experiences also affect the entrepreneurial motivation of social entrepreneurs. Some studies point out that individual social values are the product of their own experiences and social perceptions. Childhood trauma, low academic discrimination, job insecurity could change individuals' perception of their surrounding environment, promoting the occurrence of prosocial behaviors [9]. For example, private entrepreneurs with adverse social experiences, such as limited educational opportunities, unemployment and rural poverty, are also more likely to participate in charitable poverty reduction programs. In addition, social entrepreneurs, like traditional entrepreneurs, still need to have the basic ability to piece together resources and organize management. They need to deal with more complex organizational matters in order to meet the expectations of more diverse stakehold- 
ers. Although they have their own pro-social goals, they also have to take commercial actions to obtain economic income, so as to meet the sustainable development of enterprises.

In general, research on social entrepreneurs has shifted from identity definition to analysis of entrepreneurial motivations and behaviors. However, it is unclear that which specific behaviors of social entrepreneurs are more effective in promoting entrepreneurial success and what kind of emotional appeals contribute to the relevant behavioral choices. We can further increase the analysis of resource acquisition from the individual micro-level in the future. In this respect, Free and his colleagues have provided some thoughts, but we still know very little about individual entrepreneurs. In order to enrich the understanding of entrepreneurs, we can consider exploring the cognition and emotion in the process of entrepreneurs' resource acquisition. Finally, the survival and development of social enterprises not only require entrepreneurs to have pro-social motives, but also require them to implement entrepreneurial behavior with certain economic intentions. So the question, that is how social entrepreneurs should balance their intrinsic social value pursuits and external economic goals, remains to be further studied.

\section{Research on Social Entrepreneurial Organizations}

Social entrepreneurship organization is the basic unit for the implementation of social entrepreneurship activities. Some people think that it is a creative product to promote the realization of social goals, while others regard it as a new organization that engages in commercial activities only to maintain operations. However, its essence is an innovative measure to identify, evaluate and use opportunities that generate social returns to solve social problems. Non-profit social enterprises have achieved remarkable results in solving social problems through innovative business models. However, it is difficult to maintain the sustainable operation of social enterprises simply relying on charitable donations and government subsidies. Therefore, many social organizations, such as micro-credit organizations and work integration social enterprises (WISEs), are actively participating in commercial activities while pursuing social missions [10]. Their sustainability depends on the progress of social missions as well as the realization of their commercial performance. But commercialization brings special opportunities to social enterprises and also creates new challenges. On the one hand, social enterprises are organizational innovations that conform to entrepreneurs' personal values and promote institutional changes and social progress. On the other hand, commercial and social activities are competing for resources. Members of the organization are also difficult to correctly grasp how the organization chooses altruistic pro-social motives and self-interested economic goals due to cultural differences. For hybrid social organizations, how to balance their social mission and economic goals is a key dimension of their identity.

At present, the hybrid social organization has received extensive attention from 
the academic community. Especially the advantages and disadvantages of its dual identity have become a controversial topic. Proponents believe that organizations rely on stable market revenues to gain economic independence and continue to pursue social missions. Opponents criticize that market income tends to distract the attention of social organizations. Task deviation (i.e. the risk of ignoring social mission in income-generating efforts) makes it difficult for them to maintain their legal status among relevant stakeholders. Dual objectives aggravate the shortage of tangible and intangible resources. It is found that social organizations providing employment for homeless people face failure when financial funds are difficult to simultaneously support the training of organization members and commercial activities that meet customer needs. A Mexican company simultaneously hosts and educates street teenagers and produces and sells agricultural products. It shows out that business and charity activities would compete for the organization's human capital, especially the CEO's time and attention [11]. This kind of resource competition tends to weaken the organization's ability to create social value, reflecting that social mission and economic goal are mutually competitive and irreconcilable. However, now many scholars have pointed out that self-interest as the core of entrepreneurial motivation and pro-social motivation are not necessarily mutually exclusive or antagonistic. Moss et al. [12] found that these enterprises have both normative and utilitarian characteristics through analyzing the mission statements of 104 award-winning social enterprises. Other scholars have analyzed how market-oriented social enterprises combine profit-making and non-profit entrepreneurial activities to promote the process of social change. It is also found that there is a positive correlation between independent social missions and business objectives [13].

Researchers have conducted a large number of qualitative analysis of the dual identity of social organizations based on different theories and perspectives. Actually, it is difficult for social enterprises to expand their scale because of their focus on value creation [14]. Therefore, more and more researches are turning to the research on the growth and performance of social entrepreneurship organizations. At present, Stevens et al. have established the measurement dimensions of social mission and economic objectives of social entrepreneurship through high-order confirmatory factor analysis of 270 samples of social enterprises, which has laid an empirical foundation for relevant quantitative hypothesis testing. In the future, researchers can explore what strategies social organizations should adopt to balance their pursuit of social mission and economic goals, and deeply analyze how to allocate their organizational resources to achieve dual missions.

\section{Opportunities for Social Entrepreneurship: Sources, Identification and Development}

Opportunity cognition is the core of entrepreneurship and the basic ability of social entrepreneurs to solve social problems. To successfully identify and de- 
velop opportunities, social entrepreneurs need to meet two conditions. First, there are indeed many social entrepreneurial opportunities in the social environment, and such opportunities can be objectively perceived and utilized by social entrepreneurs. Second, social entrepreneurs have the objective conditions needed to identify development opportunities, such as knowledge.

\subsection{Sources of Opportunities for Social Entrepreneurship}

Entrepreneurial opportunity is a prerequisite for entrepreneurial activities. Traditional entrepreneurial opportunity refers to the situation where new products, services or organizational methods can be transferred at a price higher than their cost. It is often affected by the generation of new technologies, information asymmetry and resource substitution. However, social entrepreneurship is different, whose essence is to use market methods to solve deep-rooted social problems [15]. Social entrepreneurs not only pay attention to the premium in the process of commodity transfer, but also the positive impact of the entrepreneurial process on themselves and their surroundings. Social entrepreneurship opportunities mostly come from market failure and government function failure, closely linked to the special circumstances of entrepreneurs themselves.

The institutional environment can shape the entrepreneur's pursuit of social influence. Macroeconomic factors such as politics, social culture and taxation can affect their social value proposition and value creation concept [16]. When the government fails to meet the supply of (quasi) public goods (such as medical care) or the market fails to meet the public demand, the institutional void leaves some social demands unattended, forming opportunities or motivation for social entrepreneurship and development. For example, as the US government reduced its funding to non-profit organizations in 1980, emerging social organizations have developed rapidly by innovatively mobilizing alternative sources of funding. A similar situation occurred in Western Europe in the 1870s. The sustained high unemployment rate promoted the development of social integration enterprises serving the long-term unemployed. The lack of national social projects and the scale of government activities respectively promote and hinder the production of social enterprises. In addition, legal system and economic system are the key systems that affect social entrepreneurship. The traditional view is that the threat of legal expropriation reduces the expected entrepreneurial returns of new organizations and lead to the reduction of entrepreneurial activities. However, social entrepreneurship is just the opposite, different entrepreneurial goal significantly reducing the deterrent effect of expropriation of entrepreneurial returns. Moreover, the imperfection of law promotes the formation of social entrepreneurial opportunities. The irrational economic system has led to an endless stream of environmental problems, but it has awakened the environmental awareness of some members of society. They give birth to the idea of changing the status quo of society and actively seek to achieve an environmentally sustainable business model, becoming a special social entrepreneur-environmental 
entrepreneurs [17]. Moreover, financial instruments, including interest rates, can significantly affect the social and financial performance created by social organizations such as microfinance [18]. These findings are in line with the idea that social entrepreneurship is more likely to occur in areas where the system is empty or imperfect.

Informal system is also a key external factor affecting social entrepreneurship opportunities, of which the most critical is social culture. It directly affects the overall values of society and has an indirect impact on entrepreneurship through demand and motivation. In order to realize social influence and stimulate social change, social entrepreneurs need to establish cooperative relations with many stakeholders [19]. The social support culture (SSC), as an informal cultural norm based on friendship and support, realizes this requirement under weak social capital. It encourages more social members to choose social entrepreneurship as a career and strengthens the motivation and opportunity supply of a country's potential social entrepreneurship. Later, other scholars further find that regional cultural values can play a greater role than the national environment in influencing entrepreneurs' attitudes, behaviors and corporate growth vision. Fritsch and Wyrwich [16] specifically point out that regional entrepreneurship culture affects the dissemination of entrepreneurship models, the social acceptance of entrepreneurship and entrepreneurship support services. Huggins and Thompson also explore specific local cultures from the importance of entrepreneurial legitimacy and the role of entrepreneurial local social capital. There are several other studies that explore the relationship between different values and entrepreneurship. For example, Schwarz and his colleagues identify two values that reflect pro-social motives: kindness and universalism [20]. Inglehart and Baker [7] find that when society experiences industrialization and economic growth, the dominant values in society would shift to more interpersonal trust, quality of life, environmental protection and non-material values, thus enriching the sources of opportunities for social entrepreneurship.

In practice, the emergence of social entrepreneurship opportunities is often driven by many factors. From the perspective of system reform, both social factors and institutional environment can promote the development of social entrepreneurship. The existing research has also paid more attention to the institutional void and market failure, but rarely incorporated such background variables into specific analysis models [21]. The social system environment is very rich, including language, culture, the prevalence of crime, the nature and form of government, etc. However, existing research ignores these factors. In addition, there seems to be no research on how social entrepreneurs use various strategies to participate in and change the complex entrepreneurial system environment. In the future, we can try to analyze the environment and institutional arrangements in which different strategies would be more effective.

\subsection{Opportunity Identification of Social Entrepreneurship}

The first step in creating a new business is opportunity identification, that is, 
potential entrepreneurs find unmet needs or create new business models. There are always two perspectives in the recognition mechanism of entrepreneurial opportunities, namely "opportunity discovery perspective" and "opportunity creation perspective". The former holds that entrepreneurial opportunities exist objectively in the existing market and are independent of entrepreneurs' will, influenced by the external environment [22]. The latter holds that opportunities are formed endogenously by entrepreneurs through creative actions, reflecting their own perception of changes in the external environment [23]. Compared with the former, opportunity creation places more emphasis on the innovative interaction between entrepreneurs and the social environment. It is a process of purposefully changing the environment, aiming at promoting other groups to gradually recognize new opportunities. It is closely influenced by the problems, information and environmental changes implied in the specific fields in which entrepreneurs are located. And entrepreneurs are more likely to identify opportunities within their knowledge capabilities or social relationships. This is especially obvious in the field of social entrepreneurship. Groups troubled by social problems are more likely to find or create opportunities to realize social values. However, what is different is that the identification of social entrepreneurship opportunities needs to be promoted through dual logic, resource bricolage. Therefore, some scholars put forward the viewpoint of "opportunity co-creation" [24], explaining that it is a process in which many different participants jointly define and solve social problems. For example, through stakeholder participation and dialogue, microfinance institutions can find more effective ways to mobilize supporters to lower interest rates, thus serving poor entrepreneurs better [25]. Secondly, opportunity co-creation is a way for stakeholders to choose and construct each other. Some stakeholders are committed to rescuing the poor in remote communities, while other interest groups may be more eager to provide opportunities for female entrepreneurs. Therefore, multi-party interests compete with each other. But stakeholders can promote the transfer of new technologies and social knowledge, establish new markets and form new opportunities for social entrepreneurship in repeated interactions. For example, micro-finance institutions can adjust pro-social cost-benefit analysis in the process of mutual selection and learning, set key performance indicators (such as interest rate in social impact assessment), and continuously adjust and evaluate the roles played by various stakeholders. Opportunity co-creation creates intrinsic value for each group of stakeholders. Once opportunities and markets emerge, stakeholders follow the opportunity co-creation logic to acquire and share value and benefits like entrepreneurs when balancing interests with other stakeholders [26]. For example, micro-finance institutions can empower women to promote gender equality while reducing poverty and promoting economic development. Therefore, the negotiation and consensus of stakeholders can establish a sustainable economic and social foundation for social entrepreneurship.

Existing researches based on "opportunity discovery perspective" and "opportunity creation perspective" have explored the factors affecting opportunity 
identification from the aspects of entrepreneur's personal characteristics, cognitive logic, social network, etc. [27]. However, relevant research generally focuses on independent elements such as entrepreneurs, entrepreneurial organizations, and the external environment. They ignore the synergistic functions and roles of different elements. However, the idea of "opportunity co-creation" breaks with the norm, pointing out that social entrepreneurial opportunities are not only discovered or created by entrepreneurs, but are the results created by different participants through direct or indirect interaction. Although interactive mechanism in the entrepreneurial process has received attention, it still not been effectively studied. For example, the understanding of the interactive mechanism, antecedents and effects is still insufficient. In the future, research can be conducted on a series of issues concerning interaction mechanism, such as how various factors interact in the process of social entrepreneurship, which situational factors restrict the interaction between different factors, and the effect of different interaction modes on the co-creation of entrepreneurial opportunities.

\subsection{Opportunity Development of Social Entrepreneurship}

Social entrepreneurs pursue fundamental or innovative social changes. After identifying entrepreneurial opportunities, they will adopt various strategies and implement various decisions to continuously develop and utilize entrepreneurial opportunities to expand the social influence of the organization. In fact, social impact is regarded as one of the most important outcome variables of social entrepreneurship [28]. However, due to the differences in relevant terms and research backgrounds, their meanings have not yet formed a relatively consistent view. They are usually conceptualized through different terms such as social value, social performance, and social return on investment. Moreover, the results of social impact analysis based on different research backgrounds such as education, medical care, and environmental protection are hardly comparable. Considering the current controversy over the concept of social impact, we use Stephan's view to define social impact as a beneficial result of pro-social behavior, which is in line with the expectations of a wide range of individuals, organizations or social groups. The advantage is that it covers most of the existing methods for studying social impacts and recognizes that social impacts include many different phenomena and the complexity of target group data [29].

Although social entrepreneurs give weight to value creation rather than value acquisition, they still need to win the attention and support of stakeholders (such as donors and governments). Therefore, they focus their attention and resources on various strategies to maximize social value, mainly including diversification, horizontal expansion, scale expansion and depth expansion [30]. Diversification can help social enterprises expand the range of products or services, so as to meet new needs based on existing professional knowledge. Horizontal expansion can mobilize other actors (investors, partners, governments, etc.) to help spread and share the social innovation of the social organization. In addition, absorbing 
new beneficiaries through scale expansion is also a way to improve business design and directly expand social impact. However, in-depth expansion is different. The focus is on improving the quality of the organization's social impact rather than quantity, so it is more concerned with how to improve and enrich existing processes. Comparing the relative values of the four strategies, it is found that scale expansion is the most direct and widely used means to enhance social organizations' influence. But its implementation will face greater challenges of resource mobilization, process optimization and performance evaluation.

Maintaining capacity for sustainable development is the foundation for social enterprises to build and expand their influence. Successful social enterprises are particularly good at using social networks to catalyze change and create social value. First, lobbying stakeholder participation is an important means to convey community needs and expand influence. By communicating and persuading donors, customers and communities to support the effectiveness of their social mission values, social enterprises can avoid obstacles in the integration of resources and the acquisition of legitimacy. Second, access to government support is an effective way for social enterprises to benefit from favorable government regulations, legal norms, and regulatory changes [31]. Political activities help social enterprises to establish a trust relationship with the government and obtain scarce resources controlled by the government. It is more likely to expand new geographic markets and increase the number of their beneficiaries [32]. Then the ability to realize excess income (income greater than expenditure) is regarded as the key to a strong business model for social enterprises. According to the resource-based view, market-based income can increase the possibility of sustainable development of the organization. The ability to generate income can enhance the economic autonomy of the organization and enable it to focus on the development of social influence [33]. For example, the "service charge" mode of operation enables social enterprises to purchase subsidized charity to serve more beneficiaries. Finally, cultivating a more open organizational model is another ability to expand the influence. But it depends on the perception of the extent to which social entrepreneurs are ethical in the social environment. The higher moral requirements entrepreneurs perceive, the more likely they would choose to use a more open organizational model to create a faster and broader expansion of social innovation. On the contrary, they would adopt a more closed expansion model (e.g. branches), only hoping that the solutions can alleviate local social problems.

So far, the research on the influence of social enterprises is still mainly qualitative analysis, mostly case studies. Academic circles have not yet unified the explanation of the nature of social influence [34]. We know little about what kind of ability can effectively expand the social influence of organizations [35]. Moreover, researchers have not developed a method for scientific assessment of social influence. The obstacle lies not only in the fact that social organizations 
are difficult to realize the balance of interests of all parties, but also in the fact that the measurement process involves the assessment of subtle changes in specific events, too difficult to measure and trace back. For example, how should we measure the enhancement effect of social enterprises on the self-confidence of poor students? How could this effect be traced back to specific events (after-school plans, teaching methods, etc.)? More importantly, how could the changes in confidence be linked to the broad mission of a social enterprise that aims to provide quality education for poor students? For such problems, no corresponding solutions have been put forward. Therefore, these problems lead to the opacity of most of the basic assumptions based on the "causal chain" method (the implementation path of "input-result-influence") hindering the development of social influence research.

\section{Social Entrepreneurship Resources: Resource Acquisition and Legitimacy Construction}

\subsection{Crucial Resource Acquisition}

The resource-based view holds that key entrepreneurial resources play an important role in the creation, survival and development of new enterprises [36]. There is a need to promote resource support and maintain resource flow at all stages. Therefore, social entrepreneurship process research is to answer the question of how entrepreneurs gain legitimacy and resources. They advocate the social value proposition through opportunity identification, organization construction and influencing other members of society. This major mission of creating social values often forces them to give up all or part of their economic benefits, resulting in more prominent and complex challenges in obtaining resources.

In terms of financial capital, the capital structure plays a key role in the survival and development of enterprises. From the internal point of view, the realization of social goals requires long-term investment. Social entrepreneurs are more far-sighted than commercial entrepreneurs. Based on pro-social cost-benefit analysis, they are reluctant to subordinate the long-term non-financial goals of social enterprises (such as social and environmental goals) to financial necessities that require strict on-time debt payments. And social entrepreneurs pay less attention to how to analyze and adjust the organizational capital structure than traditional entrepreneurs. From the external point of view, evaluators (especially financial institutions) often underestimate the legitimacy of social enterprises and overestimate their investment risks as social enterprises do not conform to the traditional organizational categories. They ignore the long-term social value and economic benefits that social activities bring. For the above reasons, the capital structure of social enterprises would contain less debt financing than commercial enterprises in the long run, and its initial leverage ratio also has a greater impact on future leverage ratio than commercial enterprises [37].

Human capital is the basis to support entrepreneurs to make correct entre- 
preneurial choices and effectively implement entrepreneurial activities. It is the personal ability formed by individuals due to their knowledge, education, experience and other characteristics reflecting production value in the working environment. Therefore, one of the focuses of social entrepreneurship is to build human capital. The members of social enterprise pay more attention to job satisfaction and quality of life than their economic benefits. They also value the quality and content of work more than others in commercial enterprises. Therefore, social organizations have more inherent advantages in attracting and retaining talents and striving for voluntary labor. In addition, some social enterprises are also committed to enhancing human capital and building capabilities that benefit both individuals and communities. For example, as a social venture capital company located in rural China, Sowers Action has transformed the huge population burden into intellectual and productive resources by developing new skills. There are similar organizations in Europe, namely, Work Integration Social Enterprises (WISEs), which provide training to vulnerable groups (such as the disabled) to help them enter the labor market and achieve self-reliance. By providing skills training, expanding formal education, and arranging management experience sharing, social enterprises can increase their access to self-sufficient entrepreneurial practices and increase the human capital of the organization itself and society.

Other studies have also begun to analyze how social entrepreneurs successfully use their identities and skills to get conventional resources. For example, Wry and York [38] propose that social entrepreneurs with unique roles and identity face different opportunities and restrictions when combining business and social welfare logic, thus being more variable in designing new models and catalyzing the flow of supportive resources. When initiating fundamental changes, the identity of social entrepreneurs is not only the identity of entrepreneurs, but also their structural status in a field that enables them to access decentralized resources across different stakeholders. And social entrepreneurs with strong social skills and effective interaction with resource providers can further improve their success rate in obtaining resources.

Social entrepreneurship is a means to alleviate social problems. Most studies still emphasize the acquisition and provision of entrepreneurial resources, but ignore other more valuable forms of support, including the establishment of an entrepreneurial ecosystem [39]. This ecosystem involves interactions between multiple actors (such as customers, investors, NGOs, and governments) that effectively facilitate the flow and sharing of resources. Some studies have begun to explore the process of establishing the ecosystem. In the future, we can deeply analyze how the interaction mechanism between internal and external members of the system can effectively stimulate innovation and promote entrepreneurship growth. Regarding the acquisition of resources, there are still two omissions in the existing research. First, although the acquisition of resources involves the suppliers and demanders, researchers pay more attention to social enterprises (demanders of resources) and ignore the different resource suppliers [40]. For 
example, the different values and expectations of providers affect their decision-making logic and determine the effectiveness of social enterprise access to resources [41]. Second, the existing research on social enterprises' access to resources lacks large-scale sample analysis and comparative analysis and is mostly concentrated in a single country. Although portraying social entrepreneurs as heroes who change society can deeply analyze specific social problems, over-reliance on symbolic personal stories limit researchers' insight across research backgrounds, making it difficult for them to grasp the institutional complexity of transnational research [42]. Therefore, the introduction of cross-country comparisons for is valuable for understanding the various institutional conditions in which it is generated, operated and developed.

\subsection{Establishment of Legitimacy of Social Entrepreneurship}

As a typical "hybrid organization", social enterprises have a complex relationship with many stakeholders because of their dual missions with certain conflicting relationships [43]. They face greater obstacles to survival and severe challenges of inherent lack of legitimacy. Therefore, to win the acceptance and recognition of the identity of members of society, social organizations must cross the threshold of legitimacy and embed in the social environment through a series of legality strategies. Many researchers have actively explored the legitimacy of new ventures in combination with institutional theory, resource-based view, and entrepreneurial behavior perspective.

Institutional researchers believe that legitimacy is an acceptable and legitimate organizational behavior within certain social structure standards, values, beliefs and definition systems. From the perspective of stakeholders, legitimacy is their acceptance of organizational behavior. Different researchers have made different classifications of social legitimacy, including regulatory, normative and cognitive legitimacy, practical legitimacy and moral legitimacy, market legitimacy, investment legitimacy, relationship legitimacy, social legitimacy and alliance legitimacy. Organizations can acquire legitimacy by complying with social systems, social norms and social expectations. Meyer et al. [13] indicate that an organization can form a normative structure of legitimacy through the system of generating internal isomorphic behavior, thereby maintaining its isomorphism with its institutional environment and maximizing legitimacy. Maggio and Powell [26] further propose three institutional isomorphic pressures-mandatory isomorphism, simulated isomorphism, and normative isomorphism-that demonstrate the homogenization of organizations in the process of seeking legitimacy. However, due to the lack of clear normative logic, social entrepreneurship shows particularity in obtaining organizational legitimacy [21]. Therefore, Morgan put forward another pressure-reflexive isomorphism during the process of social entrepreneur paradigm construction, constituting the four major strategies to legalize the acquisition of social organizations. Institutional researchers believe that the new organization acquires legitimacy through homogenization behavior across social regulation, norms and cognitive barriers. The legitimacy strategy is 
more inclined to the passive and obedience strategy of institutional embedding. However, social entrepreneurs need to influence the existing institutional arrangements through active institutional entrepreneurship. They create new institutional logic, promote the transformation of social mechanisms, thus becoming the key to establish or rebuild value creation activities.

From a resource perspective, legitimacy is seen as a tool for organizations to access external resources. Social enterprises use market-oriented means to solve social problems and realize sustainable development by providing products or services (such as micro-credit for the poor and employment for the disabled) that are lacking in the current social background to the market. This feature makes social enterprises different from commercial enterprises, greatly restricted in the collection of resources. Combined with the research of system and resource dependence theory, it is pointed out that when facing the institutional controls and market uncertainty, organizations can adopt five strategies to obtain legitimacy, including acquiescence, compromise, avoidance, resistance and manipulation. The choice of strategies of different strategies directly affects the behavior practice of organizations in seeking legitimacy. Suchman [38] condenses it into three types of legality strategies, namely compliance, selection and manipulation. Zimmerman and Zeitz [22] further complement the creative strategy and pointed out that these four legality strategies are differentiated according to the extent to which the organization changes external factors. According to the order of compliance, selection, manipulation and creation, compliance strategy has the smallest change to external environment elements, while creation strategy has the largest change.

There are also many scholars from the perspective of behavior to explore social entrepreneurship resources acquisition strategy. Ahlstrom and Bruton point out that organizations can obtain different organizational legitimacy through nine ways, including establishing government ties, charitable activities, making contributions to the local community, building inter-enterprise alliances, and obtaining certification. Other studies have also found that material strategy, discourse strategy and organizational strategy are also effective to obtain legitimacy [44]. As far as social entrepreneurship organizations are concerned, meta-narrative and rhetorical devices are effective micro-behavioral strategies to obtain legitimacy, mainly involving emotional images, metaphors, analogies and expressions [45]. For example, Ruebottom finds through case studies that social entrepreneurs make good use of rhetoric strategies to achieve the consistency of innovation and system, thus obtaining legitimacy. In addition, some researchers discuss the role of language and communication in promoting access to resources. They record the use of language-based strategies in social activities (such as telling stories and using personal relationships), then find that these strategies help social enterprises quickly establish familiarity with potential partners and convince them of the potential value of social undertakings. The interaction between process participants (entrepreneurs, government agencies, and other stakeholders) also opens up new ideas for social organizations to gain external legitimacy. 
Other research results stem from Molceck et al. [46] pioneering the introduction of bricolage in the field of entrepreneurship into social entrepreneurship. They put forward the new concept of social bricolage and expand the three brand-new composition structures of social value creation, stakeholder participation and persuasion. The bricolage perspective promotes social enterprises to realize their social mission by designing creative uses, reusing and acquiring underestimated, idle or discarded resources, but there is still a limitation that not all resources can be bypassed or replaced.

All three perspectives show that the strategy of social entrepreneurs to obtain legitimacy is not only passively adapting, but also actively striving for expanding the survival and development space of social organizations. Although the research on legality has made great progress, it still has the following shortcomings. First, researchers still concentrate in the field of traditional entrepreneurship, and there is a lack of research on the acquisition mechanism of social entrepreneurship legitimacy. Second, although the existing research attaches importance to the role of legitimacy in the process of social entrepreneurship, it has not yet explored the mechanism of different types of legitimacy strategies. Specially, it is important to study the relationship between legality and social entrepreneurship growth from a dynamic perspective. Therefore, the construction path of social enterprise legitimacy still needs to be revealed, and the relevant theoretical "gap" still needs to be filled. In addition, in the future, we should further explore the internal mechanism of promoting the expansion of social enterprises' economic scale and the realization of social values, thus revealing the growth mechanism of social entrepreneurs.

\section{Evaluation of Social Entrepreneurial Opportunity Development Effect: Positive and Negative Effects}

In practice, the evaluation of the development effect of social entrepreneurship opportunities is also a challenging problem. Everything has two sides. The rise of social entrepreneurship may also produce different social and economic effects. The main subjects in the existing social entrepreneurship research are mostly non-profit or mixed organizations whose aim is to realize the social mission. These organizations focus on solving problems caused by social market failures and government function failures. They make up the market void and create social value while generating economic wealth, so most scholars are paying attention to the positive externalities of social entrepreneurship. From a personal perspective, social entrepreneurship has helped some members of society to achieve self-employment and solve the dilemma of their lives. Although there are many reasons for deciding the choice of starting a business, the adverse experience of individuals is more likely to encourage individuals to take the initiative to pursue social entrepreneurship. Some scholars have taken farmers as an example to in-depth study how the low-educated people solve their own employment problems through entrepreneurial innovation activities. It can be said that solving the problem of personal livelihood is still one of the drivers of social 
entrepreneurs. From a regional perspective, social entrepreneurship has solved some social problems and improved the social environment. Social entrepreneurs are members of society who develop new solutions to specific problems (such as persistent poverty) and meet the needs of special groups (such as the disabled and veterans). Under the condition that the social needs are difficult to be effectively met due to the empty system, individuals with strong social responsibility actively gather resources, carry out entrepreneurial activities and shoulder social missions. For example, environmental entrepreneurs take the initiative to make rational use of natural resources in a sustainable way and insist on encouraging other enterprises to choose green entrepreneurial activities. In addition, social entrepreneurship can also improve regional conflicts and promote economic prosperity and peace. From a social perspective, social entrepreneurship has promoted social change and changed the traditional concept of solidification. Social entrepreneurs are innovators and promoters in the process of sustainable social transformation. They effectively integrate resources, develop new business models, change existing institutional arrangements, and bring about positive social changes. For example, Datta and Gaily [47] found that Indian women have strengthened their economic independence and increased their contribution to family income through entrepreneurial activities, thus winning a higher voice in family status. Simultaneously, it has gradually improved the recognition and respect for women in the entire Indian society. It can be seen that in the process of solving lasting social problems, social entrepreneurship has brought about new systems related to economic, cultural and other environments and created social values. Through the implementation of commercial activities, innovative products or services are provided to drive economic development, creating economic values.

Some scholars are also unique in that they believe that even non-profit activities could bring negative externalities. They think that social entrepreneurship does fill the social problems that the government departments have not properly solved and meet the social service demand remaining from market failure. But they question that social enterprises violates the established boundaries between commercial organizations and charitable organizations, not only facing the challenge of establishing legitimacy, but also further aggravating the government's incompetence and the failure of market function. In addition, some scholars also suggest that the rise of social entrepreneurship would compete with commercial entrepreneurship for limited social resources and form market competition. On the one hand, like commercial entrepreneurship, social entrepreneurship requires talents with management skills and entrepreneurial funds that support entrepreneurial activities. Therefore, there is a contradiction between resource competition and mutual restraint. On the other hand, compared with commercial entrepreneurship, social entrepreneurship is easier to obtain government support and special preferential policies, thus inhibiting the development of commercial entrepreneurship and the rapid rise of the economy.

In general, the advantages of social entrepreneurship outweigh its disadvan- 
tages due to the unique attributes of entrepreneurial intention. Most social organizations have dual identities, both altruistic social attributes and utilitarian entrepreneurial identities. Commercial activities carried out by social organizations bring about innovations in products and services, which can provide impetus for the development of regional economy. Moreover, positive social changes triggered by social entrepreneurship can also improve the institutional environment for business entrepreneurship. Even though social entrepreneurship may partly lead to negative externalities such as government departments' lack of initiative, it is still a social innovation movement with more advantages than disadvantages in the long run.

\section{Integration Framework of Social Entrepreneurship Research}

As a complex social innovation and transformation activity, social entrepreneurship involves subjects such as social entrepreneurs and social organizations. It includes the overall process of social value creation and is a continuous logical decision-making and strategy selection process. Drawing on the Timmons's model, this study combines the research ideas proposed by Shane and Venkataraman with the identification and development and utilization of entrepreneurial opportunities as the main line. It subdivides the social entrepreneurship process, including the source and identification of social entrepreneurship opportunities and explores the interaction between the various elements in the entrepreneurial process. Therefore, according to this logic, we have constructed the overall research framework of social entrepreneurship as shown in Figure 2.

As the initiator of social entrepreneurial activities, personal characteristics and life experiences make social entrepreneurs have differences in their ability to identify social entrepreneurial opportunities. Social entrepreneurship opportunities are embedded in various social and institutional environments at the individual, regional and social levels. When the external market and the government functions fail, pro-social motivation of social entrepreneurs is strengthened. They creatively identify the entrepreneurial opportunities implied in the adverse social environment and adopt strategies such as persuasion and bricolage to assemble various resources. Then they form social entrepreneurial organizations, flexibly use various legitimacy strategies to establish organizational legitimacy,

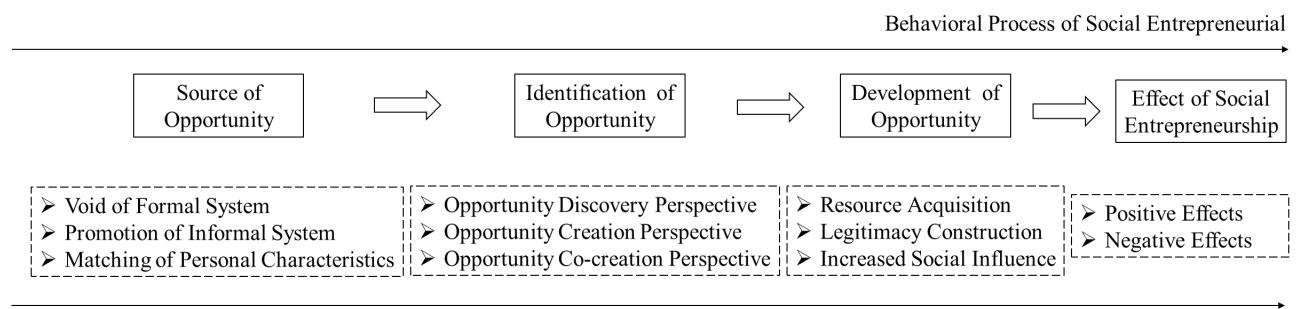

Process Elements of Social Entrepreneurship

Figure 2. Integration framework of social entrepreneurship research. Source: Author's personal arrangement. 
shoulder social missions and realize personal values. As the economic power source of social entrepreneurial activities, social organizations have both the social attribute of altruism and the entrepreneurial attribute of utilitarianism. On the one hand, they are striving to achieve social mission, on the other hand, they need to realize economic independence through commercial activities, thus showing a mixed organizational form. This dual status provides the necessary material basis for the development of its social activities, conducive to maintaining the sustainable development of the social value creation process and increasing the overall welfare of the society. To establish the legal status in the hearts of other members of the society, social entrepreneurs keep in mind the social mission, safeguard the core interests of the beneficiaries of social activities, actively change social traditional ideas and promote social change. And in the process, social organizations accumulate commercial profits and achieve economic goals, showing more positive externalities.

The origin, identification, development and utilization of social entrepreneurship opportunities are an organic and unified logical process, which is a dynamic process. Entrepreneurs rely on social organizations to adopt various measures to gather internal and external resources, establish organizational legitimacy, and maintain the sustainable development of the organization. The identification and development of opportunities has been running through. Entrepreneurs continue to optimize the development and utilization of opportunities and improve the efficiency of resource utilization in the process of continuous adjustment. Therefore, the subject, opportunities and resources are promoted cyclically in the process of social entrepreneurship. Subjects rely on initiative to identify opportunities and gather resources. Opportunities give the subjects stronger motivation to seek resources. At the same time, resources provide the necessary material basis for subjects to develop and utilize opportunities, thus forming a dynamic interactive mechanism to ensure the sustainable development of entrepreneurial activities.

\section{Future Prospect of Social Entrepreneurship Research}

This paper explores and constructs an integrated framework for social entrepreneurship research, which provides some clues for understanding the research status in this field. On this basis, this paper also further proposes the future research direction of social entrepreneurship.

Enrich the research content. First, there should be more research-based on institutional theory. Institutional entrepreneurship is not only an important branch of entrepreneurship research, but also closely related to social entrepreneurship. The emergence of social entrepreneurship opportunities is largely due to the void of the system, which makes the two have a greater overlap. Applying the theory of institutional entrepreneurship research to social entrepreneurship can explain how it solves market failures and government failures in different social institutional environments. However, there is still a lack of research to in- 
corporate the specific social institutional environment into the research model, and further attention should be paid to the factors such as culture and government characteristics in it. Second, there should be more research-based on social capital theory or resource-based view. These two theoretical viewpoints explain the interaction between social entrepreneurship situational factors and micro-foundation. In other words, the study of social entrepreneurship practice from the perspective of social capital is essentially based on the interaction between social entrepreneurs and entrepreneurship environment. Therefore, in the future, we can further analyze the specific actions of social entrepreneurs in the construction of social capital. There are so many questions to be studied, for example, which action can promote the acquisition of resources and determine the process of identification, development and utilization of social entrepreneurship opportunities, and what behavior choices entrepreneurs with different personality traits prefer to make. Finally, there should be more research-based on social psychology related theories. When analyzing a series of problems related to social entrepreneurs' motivation, opportunities and entrepreneurial behavior process, researchers often apply social psychology theory. For example, from the perspective of social cognition theory, entrepreneurs' personality traits (whether they are compassionate, in the pursuit of self-worth), and social growth experience will affect their social cognition and determine their behavioral decisions on social entrepreneurship opportunities. In the future, we can further analyze how various emotional experiences and behaviors in the entrepreneurial process affect the entrepreneurial persistence of social entrepreneurs and determine their entrepreneurial happiness.

Innovate the research methods. Although social entrepreneurship is touted as a powerful mechanism to reduce poverty and realize institutional change, the lack of large-scale empirical data hinders its real impact on the social level. At present, the relevant research mostly adopts qualitative methods such as case description and theoretical research, which makes social entrepreneurship still in the exploratory stage. Therefore, the relevant theories still need to be developed, and the structural framework to be constructed. It is necessary for future research to try to carry out comparative analysis of multiple cases, examining the laws under different conditions to strengthen theoretical construction and deeply understand the mechanism of social entrepreneurship. Or try to develop a measurement scale for social entrepreneurial performance and develop an objective indicator system, establishing a theoretical basis for empirical research. By collecting large sample data and using modern statistical analysis tools, empirical research could verify the conclusions and propositions of qualitative research from different levels and dimensions.

Broaden the research perspective. Social entrepreneurship is a multi-level organizational practice. Research that is rigidly attached to an analytical level tends to distort facts, making it difficult to understand its antecedents and outcomes. Although the existing social entrepreneurship research has gradually combined 
social entrepreneurship with existing theories or other types of entrepreneurship, the related research still needs to be deepened. Therefore, future research needs to strengthen the cross combination of social entrepreneurship and other disciplines (such as organizational behavior and sociology). In addition, the existing research focuses more on the social value creation. In the future, different social and economic effects (such as negative external economy) brought by social entrepreneurship can be emphasized.

Expand the research situation. Recently, social entrepreneurship research has gradually shifted its focus from developed countries to developing countries. As a core developing country, China has solved many social problems (such as poverty and unemployment) through social entrepreneurship activities, which naturally provides the best research situation for social entrepreneurship research. All along, China has adhered to the socialist road with Chinese characteristics and has a remarkable Chinese color in its cultural background, institutional environment, legal norms and economic system. Therefore, the researchers can take China as the research background in the follow-up research and analyze the social entrepreneurship practice in different regions of China.

This research also has the following deficiencies. Firstly, this study focuses on the process of identifying, developing and utilizing social entrepreneurship opportunities, and may ignore other important behaviors in the process of social entrepreneurship. Secondly, this study also combines the three main entrepreneurial process elements of social entrepreneurial subjects, social entrepreneurial resources and social entrepreneurial opportunities. Although the interaction among the three elements is initially explored, it still needs more in-depth research. Finally, the documents referred to in this paper are only part of a large number of studies, thus limiting the overall grasp of social entrepreneurship research.

\section{Fund Project}

1) The national natural science foundation project "Social Entrepreneurship from the Perspective of Institutional Theory: from Induction to Realization" (71872074); 2) The national natural science foundation project "Research on Social Entrepreneurial Motivation and Decision-making Behavior" (71572202).

\section{Conflicts of Interest}

The authors declare no conflicts of interest regarding the publication of this paper.

\section{References}

[1] Sutter, C., Bruton, G.D. and Chen, J. (2019) Entrepreneurship as a Solution to Extreme Poverty: A Review and Future Research Directions. Journal of Business Venturing, 34, 197-214. https://doi.org/10.1016/j.jbusvent.2018.06.003

[2] Bruton, G., Khavul, S., Siegel, D., et al. (2015) New Financial Alternatives in Seeding Entrepreneurship: Microfinance, Crowdfunding, and Peer-to-Peer Innovations. En- 
trepreneurship Theory and Practice, 39, 9-26. https://doi.org/10.1111/etap.12143

[3] Dorado, S. and Ventresca, M.J. (2013) Crescive Entrepreneurship in Complex Social Problems: Institutional Conditions for Entrepreneurial Engagement. Journal of Business Venturing, 28, 69-82. https://doi.org/10.1016/j.jbusvent.2012.02.002

[4] Saebi, T., Foss, N.J. and Linder, S. (2019) Social Entrepreneurship Research: Past Achievements and Future Promises. Journal of Management, 45, 70-95. https://doi.org/10.1177/0149206318793196

[5] Shane, S. and Venkataraman, S. (2000) The Promise of Entrepreneurship as a Field of Research. Academy of Management Review, 25, 217-226. https://doi.org/10.5465/amr.2000.2791611

[6] Dacin, M.T., Dacin, P.A. and Tracey, P. (2011) Social Entrepreneurship: A Critique and Future Directions. Organization Science, 22, 1203-1213. https://doi.org/10.1287/orsc.1100.0620

[7] Hockerts, K. (2017) Determinants of Social Entrepreneurial Intentions. Entrepreneurship Theory and Practice, 41, 105-130. https://doi.org/10.1111/etap.12171

[8] Bacq, S. and Alt, E. (2018) Feeling Capable and Valued: A Prosocial Perspective on the Link between Empathy and Social Entrepreneurial Intentions. Journal of Business Venturing, 33, 333-350. https://doi.org/10.1016/j.jbusvent.2018.01.004

[9] Oana, B., Parker, S.C., Moroz, P.W., et al. (2018) Going Pro-Social: Extending the Individual-Venture Nexus to the Collective Level. Journal of Business Venturing, 33, 551-565. https://doi.org/10.1016/j.jbusvent.2018.06.007

[10] Pache, A.C. and Santos, F. (2013) Inside the Hybrid Organization: Selective Coupling as a Response to Competing Institutional Logics. Academy of Management Journal, 56, 972-1001. https://doi.org/10.5465/amj.2011.0405

[11] Battilana, J. and Lee, M. (2014) Advancing Research on Hybrid Organizing-Insights from the Study of Social Enterprises. Academy of Management Annals, 8, 397-441. https://doi.org/10.1080/19416520.2014.893615

[12] Moss, T.W., Short, J.C., Payne, G.T., et al. (2011) Dual Identities in Social Ventures: An Exploratory Study. Entrepreneurship Theory and Practice, 35, 805-830. https://doi.org/10.1111/j.1540-6520.2010.00372.x

[13] Santos, F.M. (2012) Social Entrepreneurship in Theory and Practice: A Positive Theory of Social Entrepreneurship. Journal of Business Ethics, 111, 335-351. https://doi.org/10.1007/s10551-012-1413-4

[14] Smith, B.R., Kistruck, G.M. and Cannatelli, B. (2016) The Impact of Moral Intensity and Desire for Control on Scaling Decisions in Social Entrepreneurship. Journal of Business Ethics, 133, 677-689. https://doi.org/10.1007/s10551-014-2447-6

[15] Miller, T.L., Grimes, M.G., Mcmullen, J.S., et al. (2012) Venturing for Others with Heart and Head: How Compassion Encourages Social Entrepreneurship. Academy of Management Review, 37, 616-640. https://doi.org/10.5465/amr.2010.0456

[16] Moroz, P.W., Branzei, O., Parker, S.C., et al. (2018) Imprinting with Purpose: Prosocial Opportunities and B Corp Certification. Journal of Business Venturing, 33, 117-129. https://doi.org/10.1016/j.jbusvent.2018.01.003

[17] Mair, J., Marti, I. and Ventresca, M.J. (2012) Building Inclusive Markets in Rural Bangladesh: How Intermediaries Work Institutional Voids. Academy of Management Journal, 55, 819-850. https://doi.org/10.5465/amj.2010.0627

[18] Corbett, J. and Montgomery, A.W. (2017) Environmental Entrepreneurship and Interorganizational Arrangements: A Model of Social-Benefit Market Creation. Strategic Entrepreneurship Journal, 11, 422-440. https://doi.org/10.1002/sej.1250 
[19] Boudreaux, C.J., Nikolaev, B.N. and Klein, P. (2019) Socio-Cognitive Traits and Entrepreneurship: The Moderating Role of Economic Institutions. Journal of Business Venturing, 34, 178-196. https://doi.org/10.1016/j.jbusvent.2018.08.003

[20] Mcmullen, J.S. and Bergman, B. (2017) Social Entrepreneurship and the Development Paradox of Prosocial Motivation: A Cautionary Tale. Strategic Entrepreneurship Journal, 11, 243-270. https://doi.org/10.1002/sej.1263

[21] London, T., Esper, H., et al. (2014) Connecting Poverty to Purchase in Informal Markets. Strategic Entrepreneurship Journal, 8, 37-55. https://doi.org/10.1002/sej.1173

[22] Korsgaard, S., Berglund, H., Thrane, C., et al. (2015) A Tale of Two Kirzners: Time, Uncertainty, and the "Nature" of Opportunities. Entrepreneurship Theory and Practice, 40, 867-889. https://doi.org/10.1111/etap.12151

[23] Suddaby, R., Bruton, G.D. and Si, S.X. (2015) Entrepreneurship through a Qualitative Lens: Insights on the Construction and/or Discovery of Entrepreneurial Opportunity. Journal of Business Venturing, 30, 1-10. https://doi.org/10.1016/j.jbusvent.2014.09.003

[24] Sun, S.L. and Im, J. (2015) Cutting Microfinance Interest Rates: An Opportunity Co-Creation Perspective. Entrepreneurship Theory and Practice, 39, 101-128. https://doi.org/10.1111/etap.12119

[25] Battilana, J. and Dorado, S. (2010) Building Sustainable Hybrid Organizations: The Case of Commercial Microfinance Organizations. Academy of Management Journal, 53, 1419-1440. https://doi.org/10.5465/amj.2010.57318391

[26] Alvarez, S.A., Barney, J.B. and Anderson, P. (2016) Forming and Exploiting Opportunities: The Implications of Discovery and Creation Processes for Entrepreneurial and Organizational Research. Organization Science, 24, 301-317. https://doi.org/10.1287/orsc.1110.0727

[27] Khavul, S. (2010) Microfinance: Creating Opportunities for the Poor? Academy of Management Perspectives, 24, 58-72. https://doi.org/10.5465/amp.24.3.58

[28] Sharma, G., Beveridge, A.J. and Haigh, N. (2018) A Configural Framework of Practice Change for B Corporations. Journal of Business Venturing, 33, 207-224. https://doi.org/10.1016/j.jbusvent.2017.12.008

[29] Stephan, U., Patterson, M., Kelly, C., et al. (2017) Organizations Driving Positive Social Change a Review and an Integrative Framework of Change Processes. Journal of Management, 42, 1250-1281. https://doi.org/10.1177/0149206316633268

[30] Bacq, S. and Eddleston, K.A. (2018) A Resource-Based View of Social Entrepreneurship: How Stewardship Culture Benefits Scale of Social Impact. Journal of Business Ethics, 152, 589-611. https://doi.org/10.1007/s10551-016-3317-1

[31] Weber, C., Weidner, K., Kroeger, A., et al. (2017) Social Value Creation in Inter-Organizational Collaborations in the Not-for-Profit Sector-Give and Take from a Dyadic Perspective. Journal of Management Studies, 54, 929-956. https://doi.org/10.1111/joms.12272

[32] Gras, D. and Mendoza-Abarca, K.I. (2014) Risky Business? The Survival Implications of Exploiting Commercial Opportunities by Nonprofits. Journal of Business Venturing, 29, 392-404. https://doi.org/10.1016/j.jbusvent.2013.05.003

[33] Meyskens, M., Robb-Post, C., Stamp, J., et al. (2010) Social Ventures from a Resource-Based Perspective: An Exploratory Study Assessing Global Ashoka Fellows. Entrepreneurship Theory and Practice, 34, 661-680. https://doi.org/10.1111/j.1540-6520.2010.00389.x 
[34] Divito, L. and René, B. (2017) Entrepreneurial Orientation and Its Effect on Sustainability Decision Tradeoffs: The Case of Sustainable Fashion Firms. Journal of Business Venturing, 32, 569-587. https://doi.org/10.1016/j.jbusvent.2017.05.002

[35] Mcmullen, J.S. (2018) Organizational Hybrids as Biological Hybrids: Insights for Research on the Relationship between Social Enterprise and the Entrepreneurial Ecosystem. Journal of Business Venturing, 33, 575-590.

https://doi.org/10.1016/j.jbusvent.2018.06.001

[36] Siqueira, A.C.O., Guenster, N., Vanacker, T., et al. (2018) A Longitudinal Comparison of Capital Structure between Young For-Profit Social and Commercial Enterprises. Journal of Business Venturing, 33, 225-240. https://doi.org/10.1016/j.jbusvent.2017.12.006

[37] Tobias, J.M., Mair, J. and Barbosa-Leiker, C. (2013) Toward a Theory of Transformative Entrepreneuring: Poverty Reduction and Conflict Resolution in Rwanda's Entrepreneurial Coffee Sector. Journal of Business Venturing, 28, 728-742. https://doi.org/10.1016/j.jbusvent.2013.03.003

[38] Wry, T. and York, J. (2017) An Identity-Based Approach to Social Enterprise. Academy of Management Review, 42, 437-460. https://doi.org/10.5465/amr.2013.0506

[39] Chandra, Y. (2017) Social Entrepreneurship as Emancipatory Work. Journal of Business Venturing, 32, 657-673. https://doi.org/10.1016/j.jbusvent.2017.08.004

[40] Pahnke, E.C., Katila, R. and Eisenhardt, K.M. (2015) Who Takes You to the Dance? How Partners' Institutional Logics Influence Innovation in Young Firms. Administrative Science Quarterly, 60, 596-633. https://doi.org/10.1177/0001839215592913

[41] Jennings, P.D., Greenwood, R., Lounsbury, M.D., et al. (2013) Institutions, Entrepreneurs, and Communities: A Special Issue on Entrepreneurship. Journal of Business Venturing, 28, 1-9. https://doi.org/10.1016/j.jbusvent.2012.07.001

[42] Besharov, M.L. and Smith, W.K. (2014) Multiple Institutional Logics in Organizations: Explaining their Varied Nature and Implications. Academy of Management Review, 39, 364-381. https://doi.org/10.5465/amr.2011.0431

[43] Fisher, G., Kuratko, D.F., Bloodgood, J.M., et al. (2017) Legitimate to Whom? The Challenge of Audience Diversity and New Venture Legitimacy. Journal of Business Venturing, 32, 52-71. https://doi.org/10.1016/j.jbusvent.2016.10.005

[44] Parhankangas, A. and Renko, M. (2017) Linguistic Style and Crowdfunding Success among Social and Commercial Entrepreneurs. Journal of Business Venturing, 32, 215-236. https://doi.org/10.1016/j.jbusvent.2016.11.001

[45] Mcmullen, J.S. (2011) Delineating the Domain of Development Entrepreneurship: A Market-Based Approach to Facilitating Inclusive Economic Growth. Entrepreneurship Theory and Practice, 35, 185-193. https://doi.org/10.1111/j.1540-6520.2010.00428.x

[46] Molecke, G., et al. (2017) Accountability for Social Impact: A Bricolage Perspective on Impact Measurement in Social Enterprises. Journal of Business Venturing, 32, 550-568. https://doi.org/10.1016/j.jbusvent.2017.05.003

[47] Datta, P.B. and Gailey, R. (2012) Empowering Women through Social Entrepreneurship: Case Study of a Women's Cooperative in India. Entrepreneurship Theory and Practice, 36, 569-587. https://doi.org/10.1111/j.1540-6520.2012.00505.x 